\title{
Approach to the Weight Estimation in the Conceptual Design of Hybrid-Electric-Powered Unconventional Regional Aircraft
}

\author{
Francesco Centracchio $(\mathbb{D}$, Monica Rossetti $(\mathbb{D}$, and Umberto Iemma $(\mathbb{D})$ \\ Roma Tre University, Department of Engineering, Rome, Italy \\ Correspondence should be addressed to Francesco Centracchio; francesco.centracchio@uniroma3.it
}

Received 15 June 2018; Accepted 27 September 2018; Published 17 October 2018

Guest Editor: Vladislav Zitricky

Copyright (C) 2018 Francesco Centracchio et al. This is an open access article distributed under the Creative Commons Attribution License, which permits unrestricted use, distribution, and reproduction in any medium, provided the original work is properly cited.

\begin{abstract}
The present work deals with the development of an innovative approach to the weight estimation in the conceptual design of a Hybrid-Electric-Powered (HEP) Blended Wing Body (BWB) commercial aircraft. In the last few decades, the improvement of the environmental impact of civil aviation has been the major concern of the aeronautical engineering community, in order to guarantee the sustainable development of the system in presence of a constantly growing market demand. The sustained effort in the improvement of the overall efficiency of conventional aircraft has produced a new generation of vehicles with an extremely low level of emissions and noise, capable of covering the community requirements in the short term. Unfortunately, the remarkable improvements achieved represent the asymptotic limit reachable through the incremental enhancement of existing concepts. Any further improvement to conform to the strict future environmental target will be possible only through the introduction of breakthrough concepts. The aeronautical engineering community is thus concentrating the research on unconventional airframes, innovative low-noise technologies, and alternative propulsion systems. The BWB is one of the most promising layouts in terms of noise emissions and chemical pollution. The further reduction of fuel consumption that can be achieved with gas/electric hybridisation of the power-plant is herein addressed in the context of multidisciplinary analyses. In particular, the payload and range limits are assessed in relation to the technological development of the electric components of the propulsion system. The present work explores the potentialities of an energy-based approach for the initial sizing of a HEP unconventional aircraft in the early conceptual phase of the design. A detailed parametric analysis has been carried out to emphasise how payload, range, and degree of hybridisation are strictly connected in terms of feasible mission requirements and related to the reasonable expectations of development of electric components suitable for aeronautical applications.
\end{abstract}

\section{Introduction}

For many decades, aeronautics and air transport have been an essential component of our global society: for all countries, this industry has a substantial impact on the global economic, social, and cultural development. The civil aviation system currently involves about 29 million employees worldwide through direct, indirect, and induced activities and ensures the transfer of passengers and goods from/to the most remote areas of the planet in a constantly decreasing time. As matter of fact, the aviation industry has constantly grown throughout the last century and is expected to further increase in the near future. The average annual rate of $4.4 \%$ in terms of transport capacity (revenue passenger kilometres, RPK) experienced over the period 1989-2009 [1] is foreseen to grow to more than $5 \%$ in the 2030 horizon [2]. This growth (see Figure 1) is mostly due to the progressive access to the civil aviation system of the emerging economies (such as Asia, Middle-East, Africa, and Latin America) with more than $6 \%$ RPK annual increment during the last decades [2, 3].

Although aviation currently accounts for only 2-3\% (see Figure 2) of the 36 billion metric tons of $\mathrm{CO}_{2}$ emissions of anthropic origin [4], these emissions are projected to grow in the foreseeable future as the air traffic increases: a $75 \% \mathrm{CO}_{2}$ increment was recorded between 1990 and 2012 and it is foreseen to grow $300 \%$ by 2050 unless preventive action is taken [5]. 


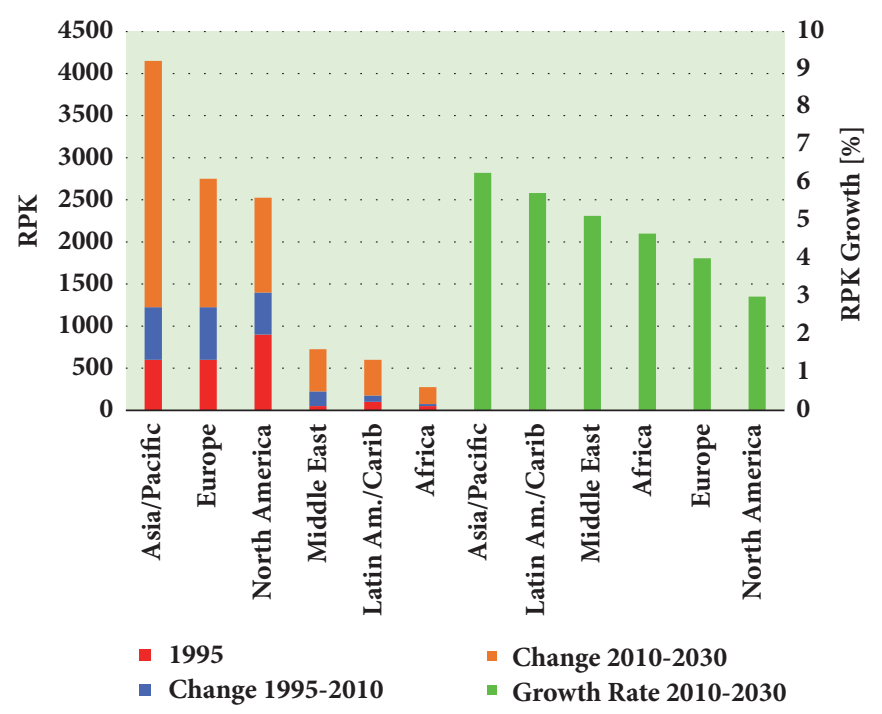

FIGURE 1: ICAO passenger traffic forecast by ICAO statistical region [9].

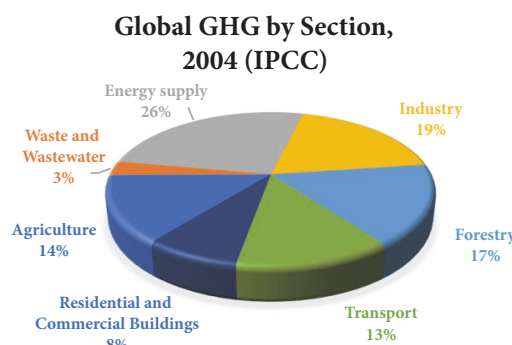

Part of Aviation

Global $\mathrm{CO}_{2}$ Emissions
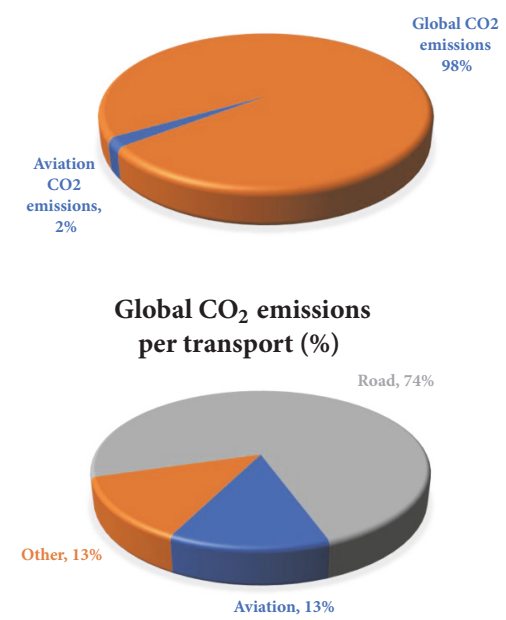

FIgURE 2: Aviation contribution to global $\mathrm{CO}_{2}$ emissions [9].

However, carbon dioxide emissions are not the only contribution to the global warming of the aeronautical transportation system. Also the water vapour, cloud formation, ozone generation, methane reduction, particulates, carbon monoxide, unburnt hydrocarbons, soot, oxides of sulphur, and nitrogen oxides should be considered [6]. For sake of clarity, $\mathrm{CO}_{2}$ and water vapour are grouped under the label Green-House-Gas (GHG) emissions responsible for the temperature of Earth's surface increase. As $90 \%$ of $\mathrm{CO}_{2}$ emissions from global commercial aircraft are associated with vehicles carrying more than 100 passengers (twin-aisle and single-aisle aircraft), research should focus on developing innovative technologies to reduce emissions for large aircraft [7]. Most likely, 
these solutions will be then suitable for smaller aircraft as well.

With regard to Paris Climate Change Conference (COP21) in 2015, where it was established to keep the global temperature rise below $2^{\circ} \mathrm{C}$ compared to preindustrial levels [8], the contribution of air transport to global warming in the near future can no longer be ignored [6].

For these reasons, since the 90 s, the international institutions involved have formulated quantitative goals for limiting Global GHG emissions establishing common targets to be fulfilled by the future aviation: $\mathrm{CO}_{2}$ emissions per RPK reduction of $60 \%$ by 2035 and $75 \%$ by 2050 with regard to reference year 2000; $\mathrm{NO}_{x}$ emissions reduction of $84 \%$ by 2035 and $90 \%$ by 2050 with regard to year 2000 .

The International Civil Aviation Organisation (ICAO) has developed since 2010 a number of measures which include technological standards, alternative fuels, operational and market-based measures aiming at promoting standards and regulations for aviation safety, security, efficiency, capacity, and environmental protection [9]. In order to concur with all the partner countries on the development of common trading schemes and policies for carbon neutral growth, ICAO established the Global Market-Based Measure (GMBM) in 2016 as an international agreement to tackle growth in carbon dioxide emissions of aviation industry from 2020 onwards $[4,6]$. This action supports the 2035 global aviation industry as carbon neutral growth ambition and seems to be a promising mean to achieve the halving of $\mathrm{CO}_{2}$ emissions by 2050 [12]. Among others, ICAO has established the Committee on Aviation and Environmental Protection (CAEP) to formulate new $\mathrm{CO}_{2}$ Standard to be applied to aircraft of the next generation [4]. However, to satisfy these long term goals not only is effort from industries sufficient but also contribution from Government Institutions is necessary, on both Research and Development (R\&D) and policy by means of, respectively, subsidises and new regulation for Air Traffic Management (ATM) [12].

Beside the environmental considerations presented, there are other motivations inducing an increasing interest in HEP aircraft. The airline companies are economically interested in reducing fuel burnt per flight due to the typical fluctuation of fuel price and its uncertain trend as fossil-fuel reserves will run short [7] (historical trend, provided by Federal Reserve Bank of St. Louis, is reported in Figure 3 for the period 01/2002-06/2018).

As it can be appreciated in Figure 4, IATA has reported in its Press-room Fact Sheets [13] that global commercial airline industry's fuel bill has been estimated to be $21 \%$ of total operating expenses in 2017 and it is foreseen to be around $24 \%$ in 2018.

As a short-term alternative to standard fuel, Sustainable Alternative Jet Fuels (SAJF) are strongly appealing the market $[7,14]$. Potential alternatives that have been intensely studied include hydrogen, blending of ethanol and bio-diesel with conventional jet fuel, nuclear power, and compressed or liquefied natural gas. Ploetner et al. in [15] reported a comparison between possible scenarios for emissions reduction by means of new aircraft fleet and procedures in 2050. All studies considered in the paper have shown that available aircraft

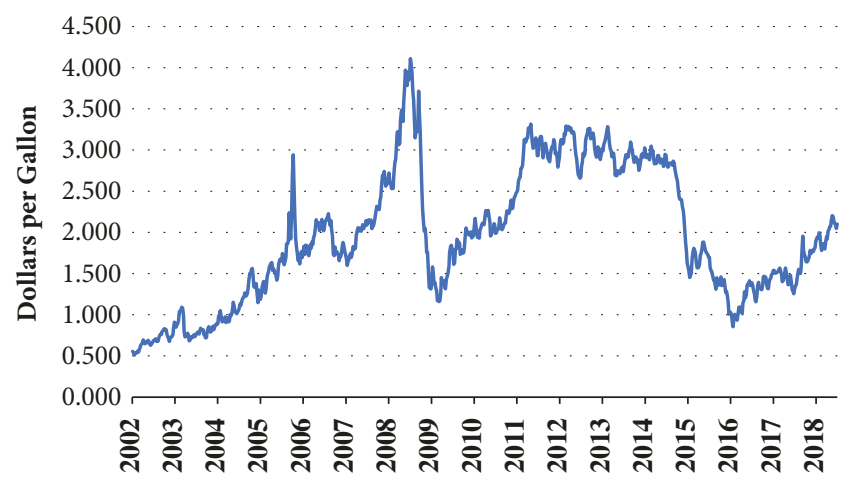

FIgURE 3: Kerosene-type jet fuel prices in US Gulf Coast [10].

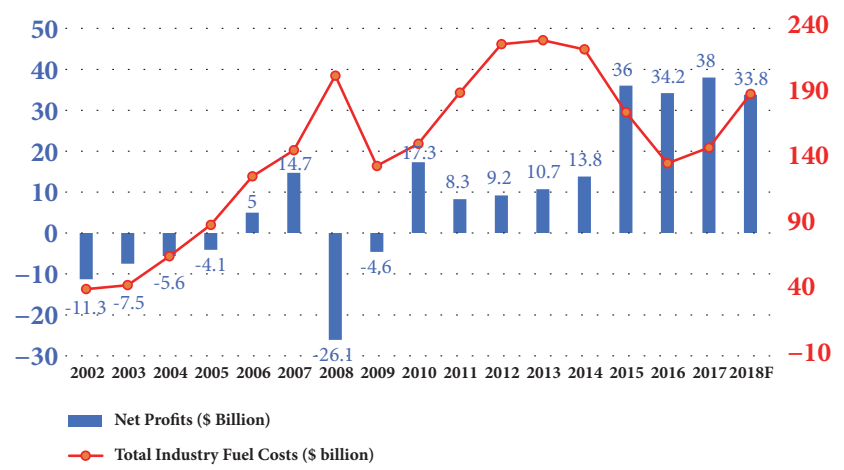

FIGURE 4: Industry fuel costs and net profits trends in aviation [11].

technology improvements are not sufficient to achieve the strict targets imposed by institutions for 2035 while air traffic grows. In a long-term scenario (2050), if novel configurations, radical technologies on aircraft level, alternative fuels, and ramp-up timelines in aircraft production are considered, GHG global emissions can be limited to 1.5 to 3.5 compared to 2005 baseline when air traffic growth is accounted.

Although dual energy sources and novel high-efficiency configurations are key aspects to accomplish the demanding request of emissions abatement, the current state of the art in specific power of each electric component and specific energy $H_{b}$ of today's batteries (as well as low energy density $\varrho_{b}$ ) is still far from being effective for aeronautical applications. All the papers dealing with the issue of hybrid aircraft state that a key role is given to the efficiency of the elements that constitute the power-plant which makes electric hybridisation appealing for the reduction of GHG emissions in aviation. It is worth noting that, despite the high gravimetric energy of fuel $H_{f}$ and the related energy density $\varrho_{f}$, the efficiency associated with conventional engine chain $\eta_{c h}^{\text {th }}$ is rather low in comparison with electrical chain $\eta_{c h}^{e l}$.

$$
\text { Conv. }\left\{\begin{array}{l}
\eta_{c h}^{t h} \simeq 0.3 \\
H_{f}=12.8 \mathrm{kWh} / \mathrm{kg} \\
\varrho_{f}=10.4 \mathrm{kWh} / \mathrm{l}
\end{array}\right.
$$




$$
\text { Elect. }\left\{\begin{array}{l}
\eta_{c h}^{e l} \simeq 0.85 \\
H_{b}=0.26 \mathrm{kWh} / \mathrm{kg} \\
\varrho_{b}=0.69 \mathrm{kWh} / \mathrm{l}
\end{array}\right.
$$

Although the technological development of electric engines, controllers, generators, inverters, batteries, etc. is not advanced enough for aeronautical applications, it is necessary to identify which specific power, specific energy, and energy density are required to have an advantage in this field.

The reason why hybridisation is nowadays not yet feasible for commercial aircraft, while it can be considered as well established for ground vehicles, is the substantial weight and volumetric penalty of the electric components caused by the high level of energy and power required. Indeed, all alternative energy sources have a volumetric energy density much lower than kerosene and consequently weight, volume, and drag penalties must be taken into account to quantify the possible advantage of substituting traditional fuel [7]. Today, the fuel is stored in the wings of aircraft in order to accomplish few specific requirements: (i) it surrounds the centre of gravity to keep its position constant while fuel is burnt; (ii) its weight counter-balance the bending moment due to the lift force; (iii) it does not affect the volume for payload. Another important aspect is the weight reduction a conventional aircraft is subjected to during the mission as fuel is burnt. The amount of lost weight depends on the scheduled range and it is of course more significant for longhaul mission. This implies that the actual energy required for a fuel-powered aircraft would definitely be less than the energy required, for the same mission, of a battery-powered aircraft. As reported in [16] the minimum gravimetric energy of batteries required in aeronautics is about $500 \mathrm{kWh} / \mathrm{kg}$ and even so, the energy storage density will be 25 times lower than jet fuel corresponding to a high volume demand and additional weight. Moreover, safety is also an important aspect to be considered: all standards must be reviewed and changed in order to account for novel propulsion systems and energy storing.

Beside technical considerations, it is also mandatory to analyse whether these technologies would be costly effective for the demand market [17]. An envisioned starting point for electrification of aircraft is the application for Urban Air Taxis or regional segment [16]: until an acceptable repayment of investment for development and operating costs would not be demonstrated, airlines will not invest in such a product. For example, in case of regional segment, an aircraft generally flies 6-8 sectors per day so that the issue of high recharging speed and long life cycle batteries to maximise the number of occurring flights will be crucial for the investors. It can be concluded that, despite the promising emission reduction foreseen for alternative propulsion systems, there still exist significant limits with regard to market demand, technological development, and regulation and integration in existing infrastructures [17]. For these reasons it is crucial that further studies will be carried out in order to achieve a 360degree view of the technological scenarios of the future.
The paper is organised as follows. Section 2 presents the main features of the BWB configuration, including the reference to a selection of works available in the literature on this specific concept. Section 3 deals with the fundamental definitions needed to address the performance analysis of a hybrid propulsion system. The conceptual approach developed in the present work is presented in Section 4, where the functional relationship between weight and hybridisation factor is obtained. Section 5 is dedicated to the analysis of the results obtained with the method presented: the region of feasible hybridisation in the space of the relevant parameters is determined through the Monte Carlo method with Latin Hypercube sampling for different mission profiles. Finally, Section 6 summarises the main outcomes of the work. Numerical simulations have been carried out using the MCRDO (Multidisciplinary Conceptual Robust Design Optimisation) framework FRIDA (Framework for Innovative Design in Aeronautics), briefly described in the Appendix.

\section{Case Study: The Blended Wing Body Concept}

The Blended Wing Body (BWB) is a tailless unconventional aircraft concept characterised by a blended functionality between the portions of the airframe dedicated to the payload allocation (the fuselage) and generation of lift (the wing). The BWB concept, with respect to tube-and-wings (TAW) layouts, turns out to have smaller aspect ratios and taper ratios. In addition, it allows to exploit a greater useful volume compared to that of the standard configurations and seems to be one of the most promising candidates for the future subsonic jetliners. It belongs to the flying-wing category and the ratio of the lifting surface to the wetted surface is increased with respect to conventional TAW layouts (see Figure 5) as well as a reduced wetted surface to volume ratio.

Several aerodynamic analyses and wind tunnel experiments have demonstrated that the lift to drag ratio is considerably improved (up to $20 \%$ with respect to classical configurations [18]), also due to the reduced interference drag. As a consequence, several advantages are foreseen, as the reduction of green-house gases emissions and the lower acoustic impact on the community. Furthermore, in several renowned studies, the benefits of BWB layout with respect to TAW configuration are given also in terms of fuel efficiency and Direct Operational Costs (DOC). Notwithstanding, it is worth noting that several issues, in both the design and the weight estimation, arise since the pressurisation of the noncircular cross-sections of the centre body is required. Moreover, due to the horizontal tail absence, the aspects concerning the longitudinal stability are crucial.

It is worth noting that, contrary to common belief, the revolutionary potential of BWB configuration over TAW layout has been grasped almost at the beginning of the aviation history [19, 20]. Several tailless biplane aircraft have been designed between 1911 and 1931, for example, the D- 8 by John Dunne and the Hill's Pterodactyl series [21]. Furthermore, even the Northrop Corporation has been engaged in the development of flying-wings: it will suffice 


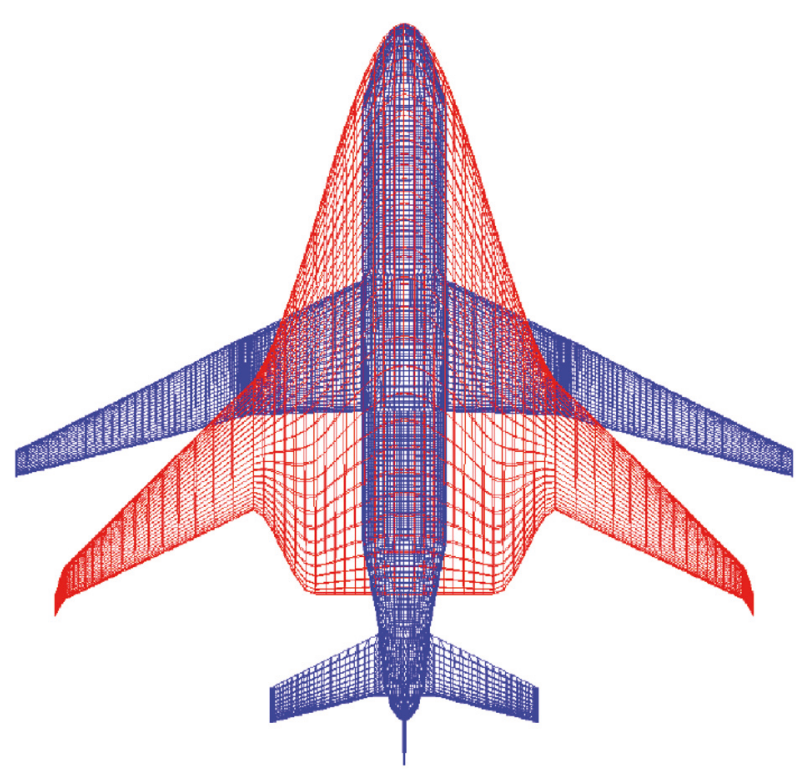

Figure 5: Comparison between tube-and-wings (TAW) and Blended Wing Body (BWB) layouts for a 110-pax class aircraft.

to consider the example of the N-1M, designed in 1940 and the N-9M [22]. Late in the World War II, the Horten Ho 229, designed in 1944 by Reimar and Walter Horten, goes down in history as the first flying-wing powered by jet engines. In 1947, another jet-powered prototype, the YB-49, has been developed by Northrop Corporation. Between 50 s and $80 \mathrm{~s}$, two concurring facts have biased the research and the development of BWB aircraft: the huge growth of the commercial aviation industry, in which the reliable and wellassessed TAW configuration ensured the market stability, and the awareness of the flying-wing potential in military industry. These factors oriented the research mainly towards military applications. Notwithstanding, due to the success of the Grumman B2 Spirit, a strategic bomber designed by the Northrop Corporation, the interest in the BWB configuration for civil applications has been reawaken. Early studies of the BWB aircraft, as it is known today, have been conducted in the late 90 s by the American aerospace company McDonnell Douglas (for a 800-pax subsonic transport aircraft with a mission of $7000 \mathrm{~nm}$ at a Mach number of 0.85 [23]), and after its merger with Boeing company an ever-increasing attention has been paid to the development of flying-wing concepts. One of the most renowned designs of a BWB is the $\mathrm{X}-48$, conceived by Boeing in cooperation with the NASA Langley Research Center. Three versions of the prototype (X-48A, $\mathrm{X}-48 \mathrm{~B}$, and $\mathrm{X}-48 \mathrm{C}$ ) have been developed between 2004 and 2012 [20]. A different BWB project was presented by Airbus Deutschland $\mathrm{GmbH}$, with the aim of comparing a two-bridge configuration with the A380 (for a mission of $7650 \mathrm{~nm}$ with 700 passengers divided into three classes [24]).

On the European side, the 5th, 6th, and 7th Framework Programs (FP5, FP6, and FP7 programs) made possible the acquisition of knowledge and skills aimed at the analysis and development of BWB configuration for civil applications.
The FP5 program includes the MOB (Multidisciplinary Optimisation of a Blended Wing Body [25]) and VELA (Very Efficient Large Aircraft [26]) projects: in the MOB project, a Computational Design Engine (CDE) for the BWB multidisciplinary design and optimisation was developed, whereas VELA analysed two BWB configurations (VELA 1 and VELA 2) used as baseline for the design of the VELA 3, a BWB aircraft powered by 4 engines mounted under the wing. During FP6, the NACRE project (New Aircraft Concept Research [27]) investigated the integration of concepts and technologies required for Novel Aircraft Concepts at aircraft component level (wing, fuselage, and engine integration) for novel aircraft. The project ACFA2020 (Active flight Control for Flexible Aircraft 2020 [28]), funded under FP7, produced the design of an innovative ultraefficient high-capacity BWB aircraft, following the ACARE guidelines. Finally, within Horizon 2020 program (H2020), the ARTEM project (Aircraft noise Reduction Technologies and related Environmental iMpact [29]) has been instituted in order to explore future aircraft configurations, as the BWB herein presented, in addition to other innovative concepts with integrated engines and distributed hybrid electric propulsion systems.

This brief (nonexhaustive) synthesis shows how not only the industry sector, but also academia always has had keen interest in the flying-wing configurations development. This fact reflects that both industries and research community are involved in the technological challenge of designing radically innovative aircraft to replace the existing, no-longersustainable fleet.

\section{Hybrid Electric Propulsion: Main Definitions}

When dealing with hybridisation of vehicles, beside choosing the power-plant that suits the application case, the designer must define whether the system is dominated by thermal or electric component [30]. For this purpose, over the years, several hybridisation parameters to quantify such domination were introduced by different authors. Some of these definitions are addressed here in chronological order.

Baumann et al. in [30] were the first to introduce the degree of hybridisation for hybrid electric vehicle $\left(\mathrm{DOH}_{\mathrm{HEV}}\right)$ defined as the ratio of the maximum power output of implied energy conversion machines in the power train

$$
D O H_{H E V}=1-\frac{\left|P_{\max , E M}-P_{\max , I C E}\right|}{P_{\max , E M}+P_{\max , I C E}}
$$

where $P_{\max }$ is the nominal power output of the electric motor (subscript EM) and internal combustion engine (subscript $I C E$ ). The authors stated that $D_{C V}=0$ is a conventional vehicle powered by ICE and $D O H_{H E V}=1$ is a fully electric configuration. By means of this parameter, the designer determines the vehicle configuration (i.e., parallel or series) and the control strategy. 
In 2004, Lukic and Emadi [31] defined the hybridisation factor to conduct a study about optimal hybridisation level for parallel-hybrid electric cars

$$
H F=\frac{P_{E M}}{P_{E M}+P_{I C E}}=\frac{P_{E M}}{P_{\text {vehicle }}=\text { const. }}
$$

where $P$ is the maximum power of electric machine (subscript $E M$ ) and internal combustion engine (subscript ICE) and $P_{\text {vehicle }}$ is the maximum total traction power to propel the vehicle. As for (2), HF can vary between 0 , for conventional, and 1 , for fully electric.

Other definitions were introduced by Buecherl et al. in [32], namely, the two hybridisation factors $H F_{1}$ and $H F_{2}$

$$
\begin{aligned}
& H F_{1}=\frac{P_{E M}}{P_{I C E}} \\
& H F_{2}=\frac{P_{E M}}{P_{E M}+P_{I C E}}
\end{aligned}
$$

where $P$ is meant as the available power for traction of the electromotive (subscript EM) and combustion (subscript $I C E$ ) engines. The authors aimed to find parameters to predict the hybrid vehicle performances, in terms of fuel consumption, additional cost and weight, reliability, and dimensions, all in once, by means of the aforementioned descriptors. Differently from the previous definitions, $H F_{1}$ can assume values from 0 up to infinity while $H F_{2}$ is bounded between 0 and 1. However, in [33] the authors assert that $H F$ descriptors do not take into account the technical and economic characteristics of energy storage devices.

The descriptor $\mathrm{HF}_{2}$ was successively adopted by Pornet et al. in [34] together with the degree of electrification (DE) previously discussed by Schmitz et al., in terms of exergy of the system, in [35].

$$
D E=\frac{E_{\text {Electric,inst. }}}{E_{\text {Total,inst. }}}
$$

This further synthesis function represents the ratio of the installed electric energy over the total installed energy to overcome the issue of accounting for the energy storage and conversion. The function DE is suitable for all kinds of energy sources (e.g., jet-fuel, bio-fuel, battery, fuel-cell, and solar panel). In [34] a parallel-hybrid architecture is analysed. The restriction to this particular power train scheme comes from the definition of power at the drive shaft used in HF descriptor.

Lorenz et al. in [36] compared several hybrid power train concepts for all kinds of vehicles, from road vehicles to aircraft. For this purpose, they found a more general definition, the degree of hybridisation $(\mathrm{DoH})$ for power

$$
H_{p}=\frac{P_{e m}}{P_{t o t}}
$$

where $\mathrm{P}$ is the maximum installed power of electric motor (subscript em) and of the sum of conventional engine and electric motor (subscript tot). Referring to the installed power, this definition is suitable for both serial and parallel systems. Moreover, because $H_{p}$ does not account for energy storage, the authors suggest the use of an additional parameter for energy

$$
H_{E}=\frac{E_{e l}}{E_{t o t}}
$$

Inspired by the Ragone gravimetric diagram for batteries, which accounts for specific power and specific energy to classify energy storage devices, in [36] the authors depicted a two-dimensional space, by means of $H_{P}$ and $H_{E}$ parameters, to identify hybrid power systems.

In 2014 Isikveren et al. used the aforementioned definitions of $H_{p}$ (ratio of maximum installed power) and $H_{e}$ (ratio of energy source storage) in [37] to introduce a sizing methodology of dual-energy storage-propulsion-power system (DESPPS) of aircraft. Introducing new parameters for the operating time of each power chain during the flight mission, namely, the activation ratio $(\phi)$, and for the supplied power, the supplied power ratio $(\Phi)$, they connected the power and energy descriptors with a functional correlation.

$$
\begin{aligned}
\phi & =\frac{\int_{0}^{T} \bar{\omega}_{b} d t}{\int_{0}^{T}\left(\bar{\omega}_{a}+\bar{\omega}_{b}\right) d t} \\
\Phi & =\frac{P_{S U P, b}}{P_{S U P, t o t}}
\end{aligned}
$$

where $\omega$ is the power control parameter of electric (b) and conventional (a) supplied power in terms of duration of use within a designed mission. In the paper, they stated $H_{p}$ to be a solely function of $\Phi$ whereas they stated $H_{E}$ to be related to both $\Phi$ and $\phi$. In [37] an example of a DoH trade study for DESPPS is reported in a diagrammatic representation, called Onion Curves, similarly as Lorenz et al. presented the Ragone diagram in [36]. In 2015, Pornet and Isikveren applied those figures of merit in [38] to quantify how hybridisation of aircraft can help reach the targets imposed by ACARE and EC.

A different approach was introduced by Marwa et al. in [39]. They define $\beta$ as the total energy mass fraction and $\chi$ as the percent hybrid parameter, provided that the energy sources operate uncoupled. Depending on the selected power-plant different equations of the modified Breguet range formulation are given.

$$
\begin{aligned}
& \chi=\frac{W_{\text {battery }}}{W_{\text {battery }}+W_{\text {fuel }}}=\frac{W_{\text {battery }}}{W_{\text {energy }}} \\
& \beta=\frac{W_{\text {energy }}}{W_{\text {energy }}+W_{\text {payload }}+W_{E O W}}
\end{aligned}
$$

By means of those parameters it is possible to write the derivatives of range and loiter equations with regard to $\chi$ variable so that a sensitivity analysis can be performed.

Recently, Voskuijl et al. in [40] analysed a parallel-hybrid configuration introducing two different approaches: constant power split $(S=c o s t)$ and constant operating mode of gas 
turbine $\left(P_{\text {em }}=P_{\text {shaft }}-P_{\text {gasturbine,const }}\right)$. The keyword of this work is to identify how and when to use the electric power. As matter of fact, beside the classic DoH parameters as defined in [37] and the activation ratio $(\phi)$, they introduced

$$
S_{i}=\frac{P_{\text {em }, i}}{P_{\text {shaft }, i}}
$$

In [40], the authors stated, when using a constant power split for all the mission phases, the supplied power ratio has approximately the same value as for the power split.

In the present study, a serial-hybrid configuration is considered as it better fits with a distributed electric fans propulsion. For this reason, the definitions of hybridisation parameters employed to investigate feasibility and benefit of dual-energy sources for aircraft are the ones referring to the electric and conventional installed powers reported in (7) and (8). Considering a constant power split for each mission segment, as suggested in [40], the DoH for power $\gamma^{H}$ and for energy $\gamma^{E}$ are linked to each other by means of the chain efficiencies so that they can be written as follows

$$
\begin{aligned}
\gamma^{H} & =\frac{P_{\text {el,inst }}}{P_{\text {tot, }, \text { inst }}} \\
\gamma^{E} & =\frac{\gamma^{H}}{\gamma^{H}+\left(1-\gamma^{H}\right)\left(\eta_{c h}^{e l} / \eta_{c h}^{t h}\right)}
\end{aligned}
$$

\section{A Conceptual Approach to Aircraft Hybridisation}

Aircraft design can be divided into three main phases, with an increasing level of detail. The first stage is the conceptual design and follows the preliminary design whereas the detail design precedes the manufacturing. It is widely felt that the conceptual phase is the most critical, as many requirements must be met (range, payload, speed specifications, etc.) together with regulatory compliance and environmental constraints. Due to this reason, in the last 20 years, optimisation techniques and conceptual design processes have made a strict dichotomy.

The conceptual stage first step is the estimation of the take-off gross weight, as long as the design mission does not include dropped payload or combat phases. The wellknown take-off weight $W_{0}$ buildup method [41] starts from considering the aircraft weight at the initial instant of its mission as it follows

$$
W_{0}=W_{c}+W_{p}+W_{f}+W_{e}
$$

$W_{c}$ being the crew weight, $W_{p}$ the payload weight, $W_{f}$ the fuel weight, and $W_{e}$ the aircraft empty weight. Note that $W_{c}$ and $W_{p}$ are known, as they are part of the mission requirements. On the contrary $W_{f}$ and $W_{e}$, which are both functions of the total aircraft weight, must be estimated with an iterative process. Specifically, it is possible to handle (16), achieving the following form

$$
W_{0}=\frac{W_{c}+W_{p}}{1-\left(\omega_{e}+\omega_{f}\right)}
$$

where $\omega_{e}=W_{e} / W_{0}$ is the empty-weight fraction with $W_{e}$ the aircraft empty weight, whereas $\omega_{f}=W_{f} / W_{0}$ is the total fuel fraction, $W_{f}$ being the weight of the fuel burnt over the entire mission. The term $\omega_{e}$ can be computed using suitable fitting relations based on historical trends, and the regression coefficients are dependent on aircraft category. Instead $\omega_{f}$, which must include the unusable fuel (about $6 \%$ of trapped fuel and reserve), can be evaluated as it follows

$$
\omega_{f}=1.06\left(1-\prod_{i=1}^{N} \frac{W_{i}}{W_{i-1}}\right)
$$

$N$ being the number of mission phases, with $W_{i-1}$ and $W_{i}$, respectively, the weight at the beginning and at the end of each phase. The fuel weight fractions related to warm-up and takeoff, climb, and landing can be estimated using historical data, whereas one can calculate the cruise fuel weight fraction $\omega_{f}^{C}$ and loiter fuel weight fraction $\omega_{f}^{E}$, by means of the Breguet equations as it follows

$$
\begin{aligned}
& \omega_{f}^{C}=\exp \left(-\frac{R}{\left.\left.\left(\eta_{p} / B S F C\right)\right|_{C}(L / D)\right|_{C}}\right) \\
& \omega_{f}^{E}=\exp \left(-\frac{E}{\left.\left.\left(\eta_{p} / B S F C\right)\right|_{E}\left(1 / V_{\infty}\right)(L / D)\right|_{E}}\right)
\end{aligned}
$$

where $R$ is the mission range, $E$ is the loiter endurance, $\eta_{p}$ is the propeller efficiency, BSFC is the brake specific fuel consumption, $L / D$ is the aerodynamic efficiency, and $V_{\infty}$ is the flight speed.

The described approach is quite inconsistent for hybrid electric aircraft, since both weight fractions $\omega_{f}$ and $\omega_{e}$ do not take into account electric components and, in particular, the weight of the battery pack which concurs to provide energy: it is therefore necessary to extend the standard weight estimation method by making some assumptions.

Let us consider the empty weight fraction $\omega_{e}$ : historical trends do not include hybrid electric aircraft, so it is not possible to include such category in the term $\omega_{e}$ in the regression used to solve (17). A valuable strategy could be the addition of the battery weight $W_{b}$ within (16), so that additional masses can be taken into account during the iterative process that bring to the take-off weight calculation. As for the empty weight and the fuel weight, it is possible to define the battery weight fraction $\omega_{b}=W_{b} / W_{0}$. Given the above, (17) can be rewritten as it follows

$$
W_{0}=\frac{W_{c}+W_{p}}{1-\left(\omega_{e}+\omega_{f}^{H}+\omega_{b}\right)}
$$

Several techniques can be used in order to achieve a good prediction of $\omega_{b}$, and the one used in this work is based on the total energy balance.

Let us focus now on the fuel weight fraction $\omega_{f}$ : by imposing the specific energies $H_{f}$ and $H_{b}$ and the conversion chain efficiencies $\eta_{c h}^{t h}$ and $\eta_{c h}^{e l}$, for a given hybridisation ratio, there could exist a certain amount of required fuel in addition 
to the batteries to fulfil the mission. Of course, in case of fully electric configurations the fuel weight fraction equals zero, since the only electric energy is used. It is therefore possible to impose a functional relation between the fuel weight fractions and the hybridisation ratio in order to rewrite (18), such as the following

$$
\begin{aligned}
\omega_{f}^{H} & =1.06\left\{1-\prod_{i=1}^{N}\left[\frac{W_{i}}{W_{i-1}}+\left(1-\frac{W_{i}}{W_{i-1}}\right) \gamma_{i}^{H}\right]\right\} \\
& =1.06\left(1-\prod_{i=1}^{N} \frac{W_{i}^{H}}{W_{i-1}^{H}}\right)
\end{aligned}
$$

$0<\gamma_{i}^{H}<1$ being a factor which takes into account the degree of hybridisation for the $i$-th mission phase. Recalling the Breguet equations, it is possible to interpret each $W_{i}^{H} / W_{i-1}^{H}$ as the weight ratio of the current mission segment for an aircraft characterised by a lower fuel consumption, which does not necessarily mean that the aircraft consumes less fuel, due to the different power sources specific energies.

\section{Results and Discussion}

In this section, the preliminary weight estimation of a hybrid electric high-capacity regional BWB aircraft is presented. In order to assess the benefits introduced by hybridisation, a comparison between a conventional propulsion system and the novel hybrid electric configuration is addressed, for the same aircraft layout and mission. The presented BWB configuration is a first-attempt sketch where it was verified that the internal volume is sufficient for passengers (cabin), fuel, cargo, auxiliaries, and batteries. It was obtained without accounting any optimisation procedure, and, consequently, there still exists margin to improve its aerodynamic performances. The case study's mission requirements are summarised in Table 1, with the main relevant parameters.

Using the classical weight estimation procedure (already implemented in the framework FRIDA), the maximum takeoff gross weight has been estimated for the fixed mission profile in which the fuel and empty weight fractions are given as output. Following this approach, a Monte Carlo with Latin Hypercube Sampling (MC-LHS) varying the mission requirements, in terms of payload and range, can be carried out in order to estimate, for each coordinate of the rangepayload plane, the required amount of fuel. In Figure 6 the obtained fuel masses are shown in a surface: the black curve identifies all those solutions for which the same amount of fuel is required, changing the payload and range parameters.

It is worth noting that the novel BWB, used for this work, has a centre-body layout such that the same payload is distributed in a shorter length (see Figure 5), without introducing space penalties, and the amount of fuel required to accomplish the mission is already lower due to the higher cruise aerodynamic efficiency with respect to a conventional configuration.

By means of the modified weight estimation algorithm, explained in the previous section, a feasibility study has been assessed within FRIDA, with regard to the technological
TABLE 1: Mission requirements and relevant parameters.

\begin{tabular}{lccc}
\hline Parameter & Symbol & Unit & Value \\
\hline Range & $\mathrm{R}$ & $\mathrm{nmi}$ & 900 \\
Payload & $\mathrm{P}$ & $\#$ & 100 \\
Crew & $\mathrm{Cr}$ & $\#$ & 5 \\
Cruise Mach & $\mathrm{M}$ & - & 0.5 \\
Altitude & $\mathrm{h}$ & $\mathrm{ft}$ & 25000 \\
Reference surface & $S_{r e f}$ & $\mathrm{~m}^{2}$ & 326.03 \\
Total span & $\mathrm{b}$ & $\mathrm{m}$ & 32.45 \\
Total length & $\mathrm{l}$ & $\mathrm{m}$ & 27.85 \\
Aerodynamic efficiency (cruise) & $(L / D)_{C}$ & - & 19.0 \\
Fuel consumption (cruise) & $\mathrm{BSFC}$ & $\mathrm{g} /(\mathrm{kWh})$ & 211.0 \\
Thermal chain efficiency (cruise) & $\eta_{c h}^{\text {th }}$ & - & 0.35 \\
Propeller efficiency (cruise) & $\eta_{p}$ & - & 0.90 \\
Fuel specific energy & $\mathrm{H}_{f}$ & $\mathrm{kWh} / \mathrm{kg}$ & 12.08 \\
\hline
\end{tabular}

development of electric components. Focusing on the battery specific energy, a maximum DoH can be estimated for some expectations of $H_{b}$ foreseen in the near future (i.e., 2035, 2050 and over). Obviously the occurring limits depend on the mission requirements: the higher the range and payload, the higher the weight of batteries which consequently brings lower feasible DoH values. The obtained results are related to the mission requirements summarised in Table 1 and are shown in Figure 7.

These curves are parametrised through the technological level of batteries, where the lower value of $H_{b}$ stands for today's specific energy of Li-ion batteries $(250 \mathrm{Wh} / \mathrm{kg})$. As it can be noted, for each curve an asymptotic limit occurs in correspondence with a certain $\gamma^{H}$ which makes the battery weight such that (21), in the iterative procedure of weight estimation, returns an indefinite value. It is interesting to highlight that a minimum specific energy of battery, required to ensure a gain in terms of fuel burnt, is between about 500 $\mathrm{Wh} / \mathrm{kg}$ and $750 \mathrm{Wh} / \mathrm{kg}$ for the presented case study.

In Figure 8 the feasible region of hybridisation has been traced performing MC-LHS analysis exploring the domain $\gamma^{H}-H_{b}$. The solutions represented by samples on the dark area are those for which about the same amount of fuel as for the conventional configuration is required, proving that hybridising the vehicle does not always provide an improvement. The area where the fuel burnt per mission starts decreasing is the right side of the oblique separation line, meaning that moving through the dark area the fuel amount remains constant. As a consequence, there will be only an increment in the gross weight without any reduction of fuel burnt. If the combination of $\gamma^{H}$ and $H_{b}$ returns a solution on the left side, it means that, despite hybridisation, the amount of fuel consumed is higher than its conventional propulsion counterpart. It is worth noting that, given today's $H_{b}$, whatever $\mathrm{DoH}$ is chosen, there is no convenience in introducing battery as additional energy sources for propulsion (see black square in the graph). Moreover, it is shown that, to have a fully electric configuration for this mission, batteries should have a specific energy of about $3.15 \mathrm{kWh} / \mathrm{kg}$. 


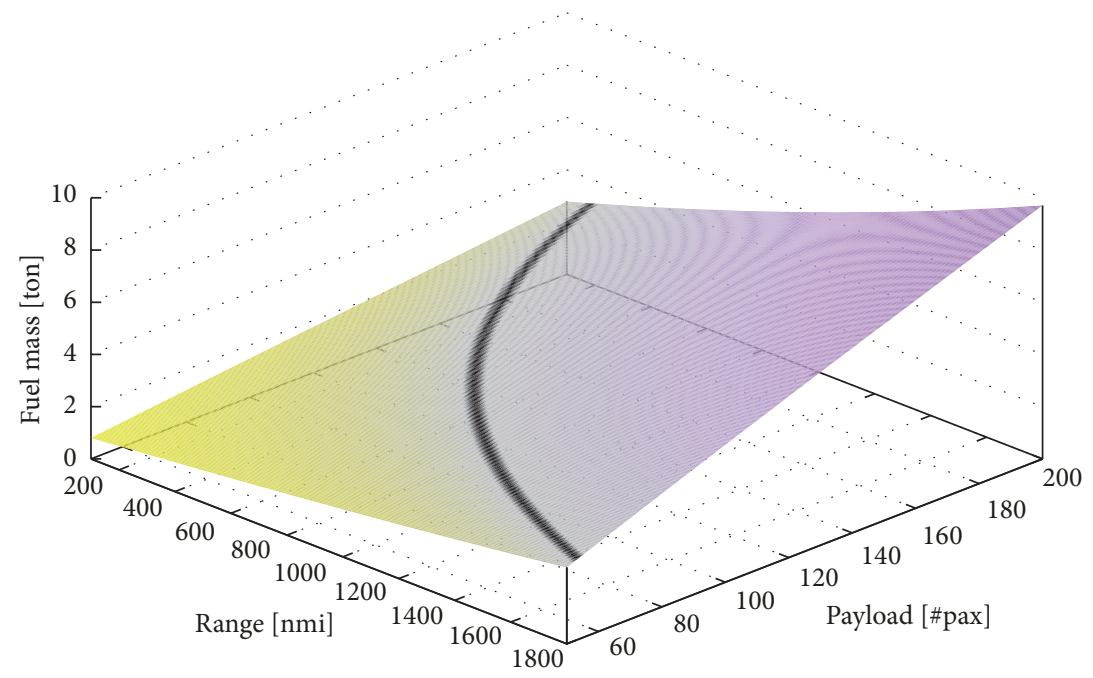

Figure 6: Maximum Take-Off Mass (MTOM) as a function of the design range and the number of passengers related to the regional BWB aircraft for $\gamma^{H}=0$ (a): the black line indicates the design solutions characterised by the same amount of fuel burnt as the reference case.

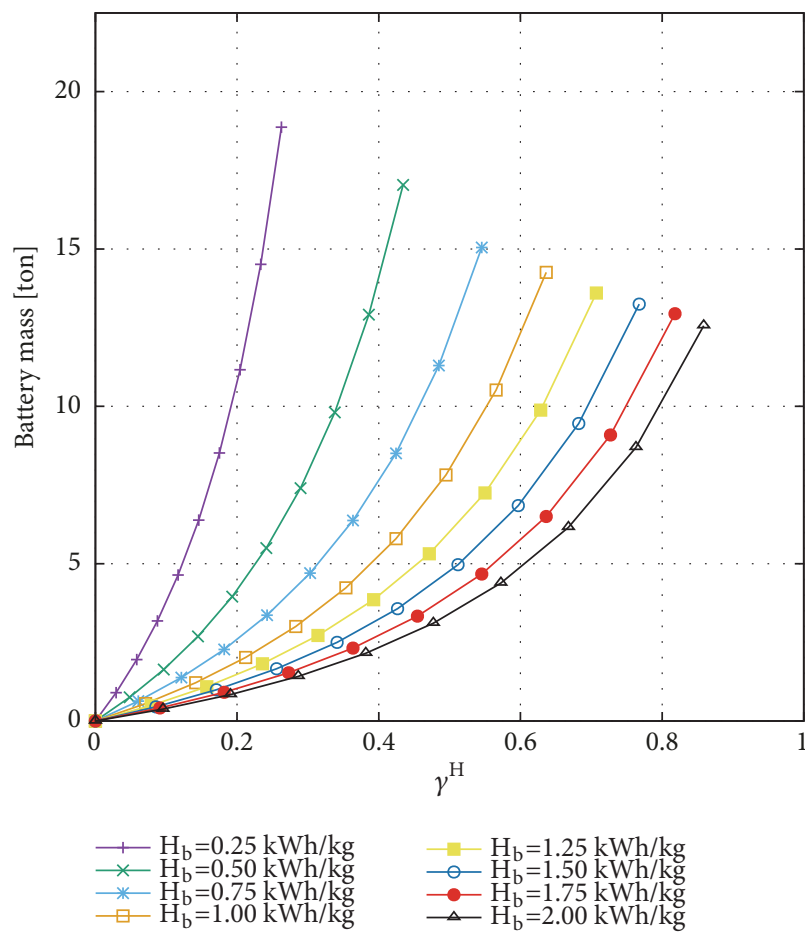

(a) Battery

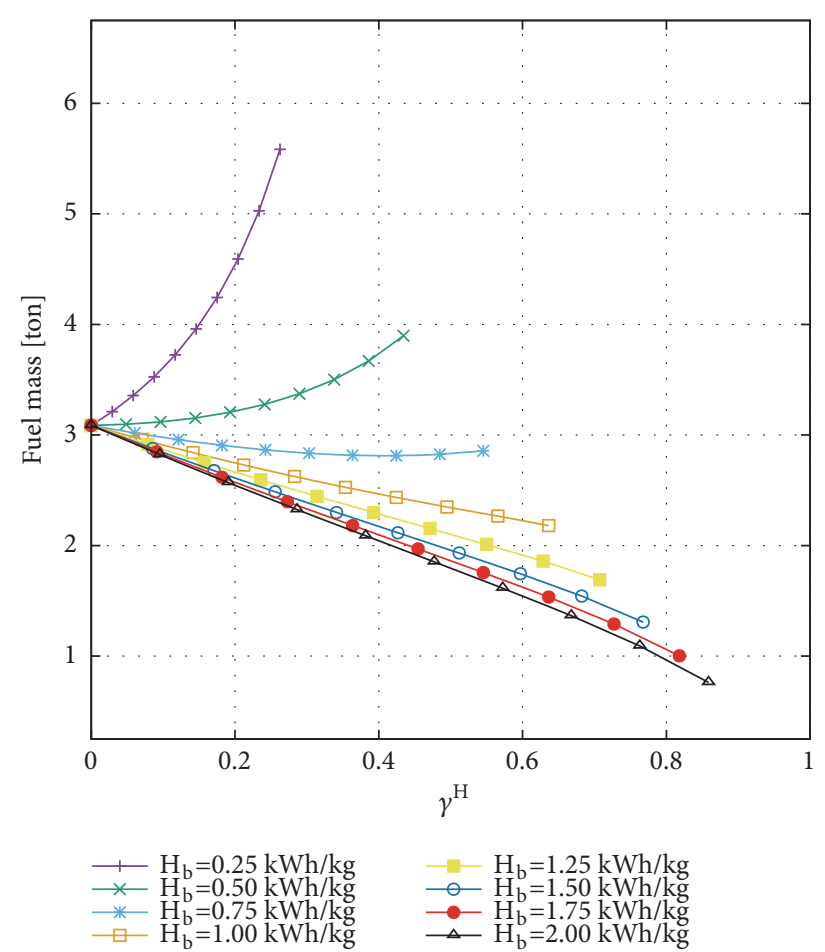

(b) Fuel

FIGURE 7: Battery-pack mass (a) and fuel mass (b) as functions of $\gamma^{H}$ related to the regional BWB aircraft, with the battery specific energy as parameter.

In order to demonstrate the aforementioned states, other design spaces have been explored. In particular, the two extreme configurations, respectively, minimum and maximum range payload, are represented by the vertexes of the surface in Figure 6. Let us first analyse the result related to the minimum range and payload (50-pax and $100 \mathrm{nmi}$ ), depicted in Figure 9.

It is worth noting how the black demarcation line changes its slope becoming about vertical and translates towards the axis origin. Therefore, it is intuitive to catch that the smaller the gross weight, the lower the required gravimetric energy to have an advantage in the hybrid electric propulsion. Moreover, the technological level required to achieve a fully electric configuration also moves towards lower values of $H_{b}$. A different behaviour can be observed for the solution at maximum range payload (200-pax and $1800 \mathrm{nmi}$ ) in Figure 10.

The demarcation line changes its slope while moving towards right, i.e. higher values of $H_{b}$. In the analysed domain 


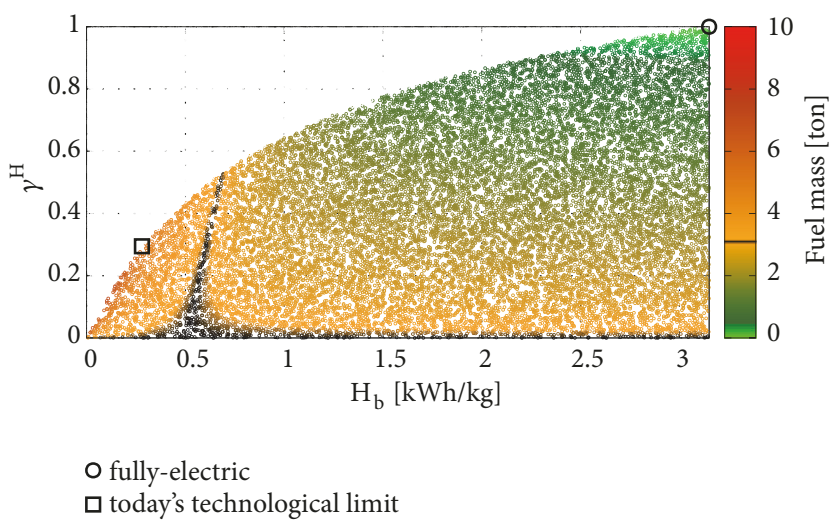

FIGURE 8: Parametric analysis of fuel mass consumption as function of degree of hybridisation and battery specific energy technology in comparison with iso-fuel solutions (black area) for the configuration characterised by mission requirements of a range of 100 -pax and 900 nmi.

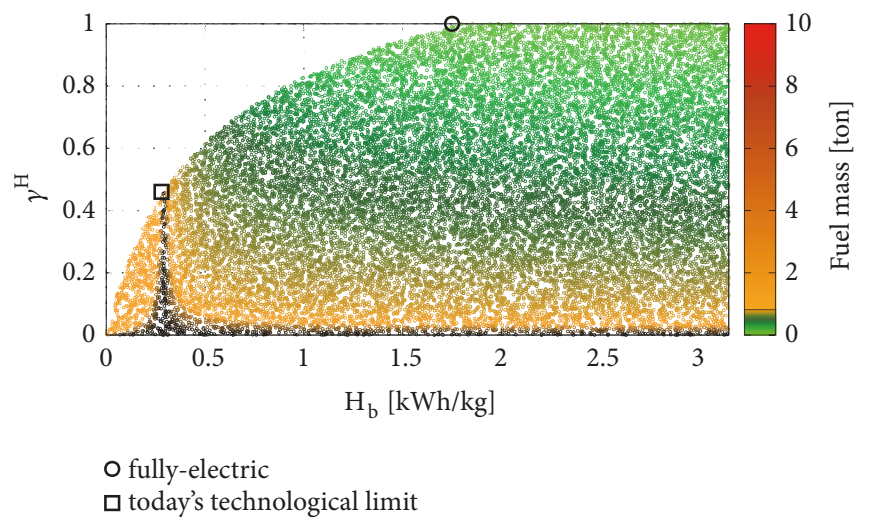

FIGURE 9: Parametric analysis of fuel mass consumption as function of degree of hybridisation and battery specific energy technology in comparison with iso-fuel solutions (black area) for the configuration characterised by mission requirements of 50-pax and a range of 100 nmi.

TABLE 2: Hybrid electric chain relevant parameters.

\begin{tabular}{lccc}
\hline Parameter & Symbol & Unit & Value \\
\hline Battery specific energy & $\mathrm{H}_{b}$ & $\mathrm{kWh} / \mathrm{kg}$ & 1 \\
State of charge & $\mathrm{SoC}$ & - & 0.20 \\
Electric chain efficiency & $\eta_{c h}^{e l}$ & - & 0.85 \\
Electric motor efficiency & $\eta_{e m}$ & - & 0.98 \\
Generator efficiency & $\eta_{g}$ & - & 0.95 \\
\hline
\end{tabular}

there does not exist any point in the design space for having a fully electric configuration. In addition, the interesting case of $H_{b} \approx 1 \mathrm{kWh} / \mathrm{kg}$ provides a gain or a loss, in terms of required fuel, depending on the selected value of $\gamma^{H}$.

Finally, from the simulations performed above, it can be concluded that, for the mission in Table 1, hybrid electric propulsion with battery and fuel as dual-energy sources is foreseen for 2050 when a specific energy of $1 \mathrm{kWh} / \mathrm{kg}$ is assumed to be a realist prevision. Given this parameter and others reported in Table 2, the modified weight estimation algorithm presented in Section 4 has been used to carry out the initial sizing of a hybrid electric propelled BWB.

For the sake of clarity, four different cases of $\mathrm{DoH}$ have been analysed:

(i) the conventional configuration with $\gamma^{H}=0$;

(ii) the case of $\gamma^{H}=0.65$, corresponding to the maximum achievable $\mathrm{DoH}$ for this mission;

(iii) the case of equal distribution between fuel and battery weight at take-off, $\gamma^{H}=0.26$;

(iv) the solution relative to the minimum utopia point distance for a biobjective optimisation problem aimed at minimising both the fuel and the battery weights, varying $H_{b}$ and $\gamma^{H}$ : the optimisation problem has been solved using FRIDA by means of MODPSO algorithm and returned the solution $\gamma^{H}=0.38$.

In Figure 11, a comparison of weight percentages with regard to the resulting MTOM of battery, fuel, payload and crew, and empty weight is shown. 


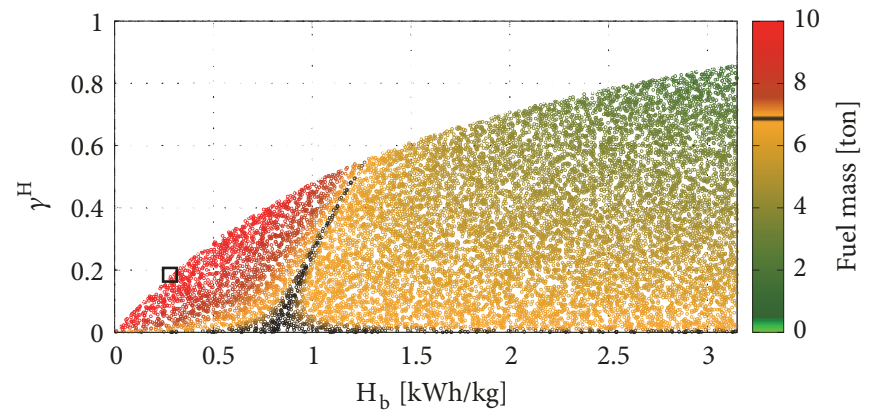

fully-electric N/A

$\square$ today's technological limit

Figure 10: Parametric analysis of fuel mass consumption as function of degree of hybridisation and battery specific energy technology in comparison with iso-fuel solutions (black area) for the configuration characterised by mission requirements of 200-pax and a range of 1800 nmi.

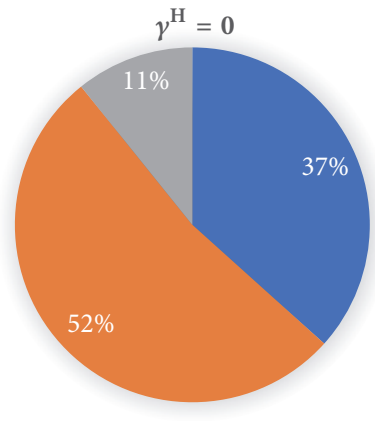

$$
\begin{aligned}
& \text { - payload \& crew } \\
& \text { - empty }
\end{aligned}
$$

(a)

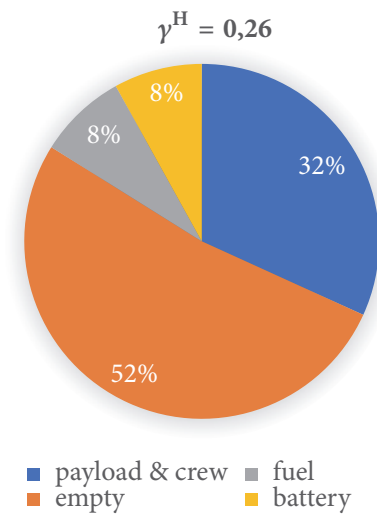

(b)

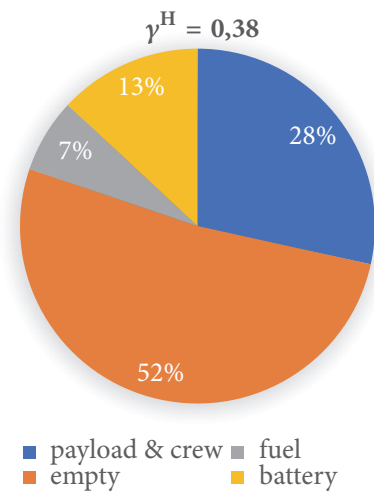

(c)

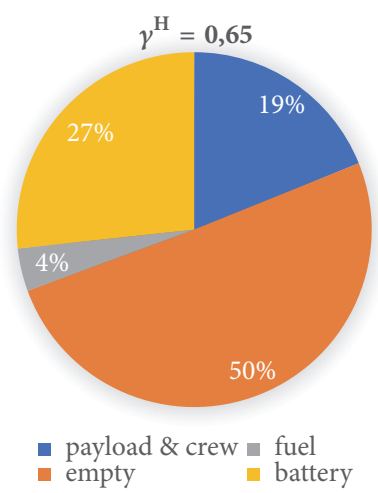

(d)

FIGURE 11: Regional high-capacity BWB aircraft MTOM breakdown for $\gamma^{H}=0$ (a), $\gamma^{H}=0.26(\mathrm{~b}), \gamma^{H}=0.38(\mathrm{c})$, and $\gamma^{H}=0.65$ (d).

As it can be deduced from Figure 11, the empty weight fraction $\omega_{e}$ is about constant as $\gamma^{H}$ increases. This is due to the overall weight increment because of the presence of the battery pack, which requires a more resistant, and consequently heavier, structure. Moreover, the masses breakdown highlights the gain in terms of fuel burnt while the hybridisation factor increases.

\section{Conclusions}

This paper explores the hybrid electric BWB aircraft configuration initial sizing methodology. Since the current technology is approaching a saturation point, innovative layouts must be defined. Accounting for the challenging targets imposed by authorities, the feasibility of introducing 
alternative energy source in aviation has become common together with the research of novel airframe design solutions. It is intuitive to understand that such dichotomy turns out to be an important technology breakthrough. Exploring the classical weight estimation methodologies to extend it for unconventional propulsion system, foreseen in the near future, is the essence of this work. After a synthesis of the main definition introduced over the last decades to account dual-energy sources for vehicle's propulsion, the modified version of the weight estimation procedure for the aircraft initial sizing has been outlined. Through the modified algorithm, several MC-LHS analyses have been performed with the aim of clarifying the functional relations between mission requirements and technological development. Results have confirmed how feasibility and technology are strictly connected to each other so that not only the achievable $\mathrm{DoH}$ but also the effective gain is left to the future technological development.

\section{Appendix}

\section{The MCRDO Framework FRIDA}

The Multidisciplinary Conceptual Robust Design Optimisation (MCRDO) framework FRIDA (Framework for Innovative Design in Aeronautics) has been used for the analyses presented in this work. FRIDA can deeply describe the aircraft from a multidisciplinary point of view, so that it turns out to be suitable for all those applications that require the aircraft configuration definition, the environmental impact estimation (taking into account both the acoustical and chemical emissions) combined with financial metrics. It is worth noting that, FRIDA being developed to assess the conceptual design of both conventional and innovative aircraft (for which the designer cannot rely on past experience or literature data), the algorithms used for the aircraft analysis are, whenever possible, prime-principle based.

The aerodynamic analysis makes use of an integral formulation based on a quasi-potential flow [42]. The formulation is coupled with a boundary-layer integral model to take into account the effects of viscosity providing an adequate estimation of the viscous drag, which is essential for the study of flight mechanics and performance analysis.

$$
\begin{aligned}
\varphi(\mathbf{x}, t)= & \int_{S_{B}}\left(G \chi-\varphi \frac{\partial G}{\partial n}\right) S(\mathbf{y}) \\
& -\int_{S_{w}}\left[\Delta \varphi_{T E}\right]^{\tau} \frac{\partial G}{\partial n} d S(\mathbf{y})
\end{aligned}
$$

The numerical solution of (A.1) is provided by a zerothorder Boundary Element Method (BEM). FRIDA can also simulate entire missions, and suitable corrections are used to take into account the aerodynamic effects of high-lift devices (flaps and slats), air-brakes, and landing gears [41]: the decision lies in the goal of reducing the computational costs, since an aerodynamic analysis at each sample of the trajectory would be too time-consuming.

The flight mechanics are solved in order to guarantee the static longitudinal stability, fundamental requirement for each flight condition, by imposing that the derivative of the pitching moment with respect to the centre of gravity is less than zero.

$$
\frac{d c_{m}}{d \alpha}<0
$$

The structural weight evaluation is addressed starting from the knowledge of the characteristic dimensions of the wing and tail elements (spars, stringers, ribs, and coverings) and the fuselage geometric sketch: subsequently the weights of engines, landing gear, and fixed equipment are added. An accurate analysis of masses distribution at each sample of the trajectory (including payload, crew, fuel, and operational items) allows the estimation of the actual position of the centre of gravity.

A 6-DOF torsional-bending beam equivalent model of the wing is assessed within FRIDA, and the nodal generalised forces due to the aerodynamic loads are computed. The modes of vibration and the natural frequencies of the beam representing the wing are also calculated. The solution of the structural problem is determined using a modal approach considering constant boundary conditions in the joint sections of wings and tail surfaces with the fuselage or the centre body in the BWB configuration. The approximate modes of vibration are calculated with a Finite Element Method (FEM) model of the wing, using the following representation for the displacements

$$
\mathbf{u}(\mathbf{x}, t)=\sum_{m=1}^{M} q_{m}(t) \Phi_{m}(\mathbf{x})
$$

The solution of (A.3) allows the estimation of the diagonal matrix $\Omega$ of the natural frequencies of the beam representing the wing. The module also evaluates the nodal generalised forces due to the aerodynamic loads acting on the wing, thus the direct and shear stresses distributions: this allows computing both the normal and the shear stress at the wing root location.

The flutter and divergence speeds estimation is also performed in FRIDA. To carry out an efficient aeroelastic analysis, a reduced order model (ROM) based on a finite-state approximation is employed for the evaluation of the matrix collecting the aerodynamic forces [43].

The analysis of entire mission requires the knowledge of the engine operating points at each sample of the trajectory. Since the complete engine thermofluidynamical analysis would be too burdensome, a semiempirical turbofan model, based on both prime-principle and available experimental data, is implemented within FRIDA. For a given flight condition, knowing the engine features, such a model provides the percentage of throttle as a function of the flight mechanics variables (altitude, drag force, actual aircraft weight, acceleration of the aircraft, etc.) and the propulsion system characteristics (number of engines, engine pitch, bypass ratio, maximum thrust per engine at sea level, etc.). For each operating point, the jets velocity is calculated through the momentum equation and their temperatures are estimated with the energy balance. Thereafter the amount 
of fuel consumed is also estimated, in order to update the current aircraft weight.

The aeroacoustic models within FRIDA allow the estimation of the airframe noise [44, 45], the fan/compressor noise [46] and the buzz-saw noise [47] as a function of the distance from the observers, the directivity (polar and azimuthal) angles, and the actual aircraft configuration, in terms of wet surfaces and engine operating point. The jet noise is evaluated by means of polynomial regressions of experimental data. For the calculation of the $1 / 3$ octave band Sound Pressure Level (SPL), the algorithms also take into account the Doppler effect, the atmospheric absorption [48], and the ground reflection. Through a proper postprocessing, the Sound Exposure Level (SEL) and the Effective Perceived Noise Level (EPNL) are also estimated. Moreover FRIDA includes an innovative sound quality assessment method [49-52], developed during progression of EC-funded SEFA (Sound Engineering For Aircraft, FP6, 2004-2007) and COSMA (Community Noise Solutions to Minimise aircraft noise Annoyance, FP7, 2009-2012) projects. In addition, suitable metamodels for taking into account the noise shielding effects for BWB configuration have been recently implemented [53, 54].

FRIDA also includes a financial module which allows the estimation of financial implications from an airline company perspective [55-57]. Positive cash flows (related to revenues) and negative cash flows (fuel and maintenance costs, and social costs related to noise pollution) are estimated and actualised in order to estimate the Net Present Value NPV of the airliner.

The single-objective minimisation algorithms implemented in FRIDA are the sparse-SQP, Sequential Quadratic Programming [58, 59], and the FORTRAN GA, a Genetic Algorithm developed by [60]. The multiobjective minimization algorithms are two gradient-free methods. The first is the NSGA-II, Non-dominated Sorting Genetic Algorithm, described by [61]. The second one, recently implemented, is a Particle Swarm Optimisation (PSO) algorithm, introduced by [62]: the PSO implementation peculiarity lies in the deterministic distribution (MODPSO) of the particles and has been developed by the Resistance \& Optimisation Team $[63,64]$ of the CNR-INSEAN (a detailed analysis of the impact on the solution due to the initial particles position can be found in literature [63], as well as an initial comparison between the NSGA-II and the MODPSO efficiencies [52]).

\section{Data Availability}

The data used to support the findings of this study may be released upon application to the coordinator of the ARTEM project (H2020, grant agreement No. 769350), who can be contacted through the third author at umberto.iemma@uniroma3.it.

\section{Conflicts of Interest}

The authors declare that they have no conflicts of interest.

\section{Acknowledgments}

This research has received funding from the European Union's Horizon 2020 research and innovation programme under project ARTEM (Aircraft noise Reduction Technologies and related Environmental iMpact) grant agreement No. 769350 .

\section{References}

[1] The International Bank fir Reconstruction and Development, "Air Transport and Energy Efficiency," 2012.

[2] AIRBUS Global Market Forecast, Growing Horizons 2017/2036, 2017.

[3] IATA, "Passenger demand," Tech. Rep., International Air Transport Association, 2018.

[4] ICAO, "Environmental report 2016," Tech. Rep., International Civil Aviation Organization, 2016.

[5] ICAO, "Environment giacc-4," Tech. Rep., International Civil Aviation Organization, 2012.

[6] M. Cames, J. Graichen, and H. Pulles, "Issues at stake at the 10th session of the ICAO committee on avitaion environmental protection (CAEP/10)," Tech. Rep., European Parlament (EU), 2016.

[7] "National Academies of Sciences, Engineering, and Medicine. Commercial Aircraft Propulsion and Energy Systems Research: Reducing Global Carbon Emissions," 2016.

[8] United Nations, "Paris agreement," Tech. Rep., 2015.

[9] ICAO, “Environmental report 2010,” Tech. Rep., International Civil Aviation Organization, 2010.

[10] U.S. Energy Information Administration, "Kerosene-Type Jet Fuel Prices: U.S. Gulf Coast [WJFUELUSGULF]," Federal Reserve Bank of St. Louis, 2018, https://fred.stlouisfed.org/ series/WJFUELUSGULF.

[11] IATA, "Industry Economics Performance Table - Forecast Table," 2018, https://www.iata.org/pressroom/facts_figures/ fact_sheets/Documents/fact-sheet-fuel.pdf.

[12] Sustainable Aviation, “CO2 road-map,” Tech. Rep., Sustainable Aviation U.K., 2016.

[13] IATA, "Fact sheet fuel," Tech. Rep., International Air Transport Association, 2018.

[14] ICAO, "Conference on aviation and alternative fuels," Tech. Rep., International Civil Aviation Organization, 2017.

[15] K. O. Ploetner, R. Raoul, M. Urban, M. Hornung, G. Tay, and O. Oguntona, "Technological and operational scenarios on aircraft fleet-level towards ATAG and IATA 2050 emission targets," in Proceedings of the 17th AIAA Aviation Technology, Integration, and Operations Conference, 2017, USA, June 2017.

[16] R. Thomson, N. Sachdeva, M. Nazukin, and N. Martinez, Aircraft electrical propulsion the next chapter of aviation? Roland Berger LTD, 2017.

[17] "EC. Flightpath 2050, europe's vision for aviation," Tech. Rep., European Commission, 2011.

[18] N. Qin, A. Vavalle, A. Le Moigne, M. Laban, K. Hackett, and P. Weinerfelt, "Aerodynamic considerations of blended wing body aircraft," Progress in Aerospace Sciences, vol. 40, no. 6, pp. 321343, 2004.

[19] R. Merino-Martinez, "Design and analysis of the control and stability of a blended wing body aircraft," 2014 . 
[20] P. Okonkwo and P. Chukwuemeka, "Conceptual design methodology for blended wing body aircraft," 2016.

[21] R. M. Wood and S. X. S. Bauer, "Flying wings / flying fuselages," in Proceedings of the 39th Aerospace Sciences Meeting and Exhibit, USA, January 2001.

[22] T. Ikeda, "Aerodynamic analysis of a blended-wing-body aircraft," 2006.

[23] R. H. Liebeck, "Design of the Blended Wing Body Subsonic Transport," Journal of Aircraft, vol. 41, no. 1, pp. 10-25, 2004.

[24] S. M. Lee, "Konzeptionelle Untersuchung einer Flying Wing Zweideckkonfiguration," 2003.

[25] Community Research and Development Information Service, "MOB: A computational design engine incorporating multi-disciplinary design and optimisation for blended wing body configuration," 2003, https://cordis.europa.eu/project/ rcn/54240_en.html.

[26] Community Research and Development Information Service, "VELA: Very efficient large aircraft," 2005, https://cordis .europa.eu/project/rcn/64926_en.html.

[27] Community Research and Development Information Service, "NACRE: New aircraft concepts research," 2010, https://cordis.europa.eu/project/rcn/75773_en.html.

[28] Community Research and Development Information Service, "ACFA2020: Active Control for Flexible 2020 Aircraft," 2011, https://cordis.europa.eu/project/rcn/88419_en.html.

[29] Community Research and Development Information Service, "ARTEM: Aircraft noise Reduction Technologies and related Environmental iMpact," 2017, https://cordis.europa.eu/project/ rcn/212367_en.html.

[30] B. M. Baumann, G. Washington, B. C. Glenn, and G. Rizzoni, "Mechatronic design and control of hybrid electric vehicles," IEEE/ASME Transactions on Mechatronics, vol. 5, no. 1, pp. 5872, 2000.

[31] S. M. Lukic and A. Emadi, "Effects of drivetrain hybridization on fuel economy and dynamic performance of parallel hybrid electric vehicles," IEEE Transactions on Vehicular Technology, vol. 53, no. 2, pp. 385-389, 2004.

[32] D. Buecherl, I. Bolvashenkov, and H. G. Herzog, "Verification of the optimum hybridization factor as design parameter of hybrid electric vehicles," in Proceedings of the International Symposium on Power Electronics, Electrical Drives, Automation and Motion, SPEEDAM 2006, May 2006.

[33] I. Bolvashenkov, H.-G. Herzog, and A. Engstle, "Factor of hybridization as a design parameter for hybrid vehicles," in Proceedings of the International Symposium on Power Electronics, Electrical Drives, Automation and Motion, 2006. SPEEDAM 2006, pp. 926-929, Italy, May 2006.

[34] C. Pornet, C. Gologan, P. C. Vratny et al., "Methodology for sizing and performance assessment of hybrid energy aircraft," Journal of Aircraft, vol. 52, no. 1, pp. 341-352, 2015.

[35] O. Schmitz and M. Hornung, "Unified Applicable Propulsion System Performance Metrics," Journal of Engineering for Gas Turbines and Power, vol. 135, no. 11, p. 111201, 2013.

[36] L. Lorenz, A. Seitz, H. Kuhn, and A. Sizmann, "Hybrid power trains for future mobility," 2013.

[37] A. T. Isikveren, S. Kaiser, C. Pornet, and P. C. Vratny, "Predesign strategies and sizing techniques for dual-energy aircraft," Aircraft Engineering and Aerospace Technology, vol. 86, no. 6, pp. 525-542, 2014.

[38] C. Pornet and A. T. Isikveren, "Conceptual design of hybridelectric transport aircraft," Progress in Aerospace Sciences, vol. 79, pp. 114-135, 2015.
[39] M. Marwa, S. M. Martin, B. C. Martos, and R. P. Anderson, "Analytic and numeric forms for the performance of propellerpowered electric and hybrid aircraft," in Proceedings of the 55th AIAA Aerospace Sciences Meeting, USA, January 2017.

[40] M. Voskuijl, J. van Bogaert, and A. G. Rao, "Analysis and design of hybrid electric regional turboprop aircraft," CEAS Aeronautical Journal, vol. 9, no. 1, pp. 15-25, 2018.

[41] D. P. Raymer, Aircraft Design: a Conceptual Approach, AIAA, Washington, DC, USA, 1992.

[42] L. Morino, "Boundary integral equations in aerodynamics," Applied Mechanics Reviews, vol. 46, no. 8, pp. 455-466, 1993.

[43] L. Morino, F. Mastroddi, R. De Troia, G. L. Ghiringhelli, and P. Mantegazza, "Matrix fraction approach for finite-state aerodynamic modeling," AIAA Journal, vol. 33, no. 4, pp. 703711, 1995.

[44] M. R. Fink, “Approximate prediction of airframe noise," Journal of Aircraft, vol. 13, no. 11, pp. 833-834, 1976.

[45] M. R. Fink, "Airframe Noise Prediction Method," Tech. Rep., FAA, 1977.

[46] C. L Morfey and M. J. Fisher, "Shock-wave radiation from supersonic ducted rotor," The Aeronautical Journal, vol. 74, no. 715, pp. 579-585, 1970.

[47] M. F. Heidmann, "Interim prediction method for fan and compressor source noise," Tech. Rep., NASA, 1979.

[48] L. C. Sutherland, J. E. Piercy, H. E. Bass, and L. B. Evans, "Method for calculating the absorption of sound by the atmosphere," The Journal of the Acoustical Society of America, vol. 56, no. S1, pp. S1-S1, 1974.

[49] U. Iemma, M. Diez, and V. Marchese, "Matching the aircraft noise to a target sound: A novel approach for optimal design under community noise constraints," in Proceedings of the 13th International Congress on Sound and Vibration 2006, ICSV 2006, pp. 3643-3650, Austria, July 2006.

[50] U. Iemma, M. Diez, C. Leotardi, and F. Centracchio, "On the use of noise annoyance as a design optimization constraint: The COSMA experience," in Proceedings of the 18th International Congress on Sound and Vibration 2011, ICSV 2011, pp. 426-433, Brazil, July 2011.

[51] M. Diez and U. Iemma, "Multidisciplinary conceptual design optimization of aircraft using a sound-matching-based objective function," Engineering Optimization, vol. 44, no. 5, pp. 591$612,2012$.

[52] U. Iemma, L. Burghignoli, F. Centracchio, and V. Galluzzi, "Multi-objective optimization of takeoff and landing procedures: Level abatement vs quality improvement of aircraft noise," in Proceedings of the 43rd International Congress on Noise Control Engineering: Improving the World Through Noise Control, INTERNOISE 2014, Australia, November 2014.

[53] L. Burghignoli, F. Centracchio, U. Iemma, and M. Rossetti, "Multi-objective optimization of a BWB aircraft for noise impact abatement," in Proceedings of the In 25th International Congress on Sound and Vibration, ICSV25, Hiroshima, Japan, 2018.

[54] F. Centracchio, L. Burghignoli, M. Rossetti, and U. Iemma, "Noise shielding models for the conceptual design of unconventional aircraft," in Proceedings of the In 47th International Congress and Exposition on Noise Control Engineering, InterNoise, Chicago, Illinois, USA, 2018.

[55] U. Iemma, F. P. Vitagliano, and F. Centracchio, "Life-cycle costs and infrastructural investments induced by unconventional low-noise aircraft," in Proceedings of the 44th International 
Congress and Exposition on Noise Control Engineering, INTERNOISE 2015, USA, August 2015.

[56] U. Iemma, F. Pisi Vitagliano, and F. Centracchio, "Multiobjective design optimization of sustainable commercial aircraft: performance and costs," International Journal of Sustainable Engineering, vol. 10, no. 3, pp. 147-157, 2017.

[57] U. Iemma, F. Pisi Vitagliano, and F. Centracchio, "A multiobjective design optimisation of eco-friendly aircraft: the impact of noise fees on airplanes sustainable development," International Journal of Sustainable Engineering, pp. 1-13, 2017.

[58] P. E. Gill, W. Murray, and M. A. Saunders, "SNOPT: an SQP algorithm for large-scale constrained optimization," SIAM Review, vol. 47, no. 1, pp. 99-131, 2005.

[59] J. F. Bonnans, J. C. a. Gilbert, and C. A. Sagastizabal, Numerical Optimization: Theoretical and Practical Aspects, Springer, Berlin, Germany, 2006.

[60] D. L. Carroll, "Chemical laser modeling with genetic algorithms," AIAA Journal, vol. 34, no. 2, pp. 338-346, 1996.

[61] K. Deb, A. Pratap, S. Agarwal, and T. Meyarivan, "A fast and elitist multiobjective genetic algorithm: NSGA-II," IEEE Transactions on Evolutionary Computation, vol. 6, no. 2, pp. 182197, 2002.

[62] J. Kennedy and R. Eberhart, "Particle swarm optimization," in Proceedings of the IEEE International Conference on Neural Networks, pp. 1942-1948, Perth, Australia, December 1995.

[63] E. F. Campana, M. Diez, G. Fasano, and D. Peri, "Initial Particles Position for PSO, in Bound Constrained Optimization," in Proceedings of the 4th International Conference, ICSI, 2013.

[64] M. Diez, A. Serani, C. Leotardi et al., "A Proposal of PSO Particles' Initialization for Costly Unconstrained Optimization Problems: ORTHOinit," in Advances in Swarm Intelligence, vol. 8794 of Lecture Notes in Computer Science, pp. 126-133, Springer International Publishing, Cham, 2014. 


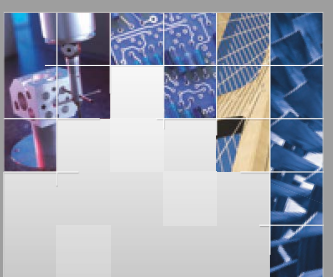

\section{Enfincering}
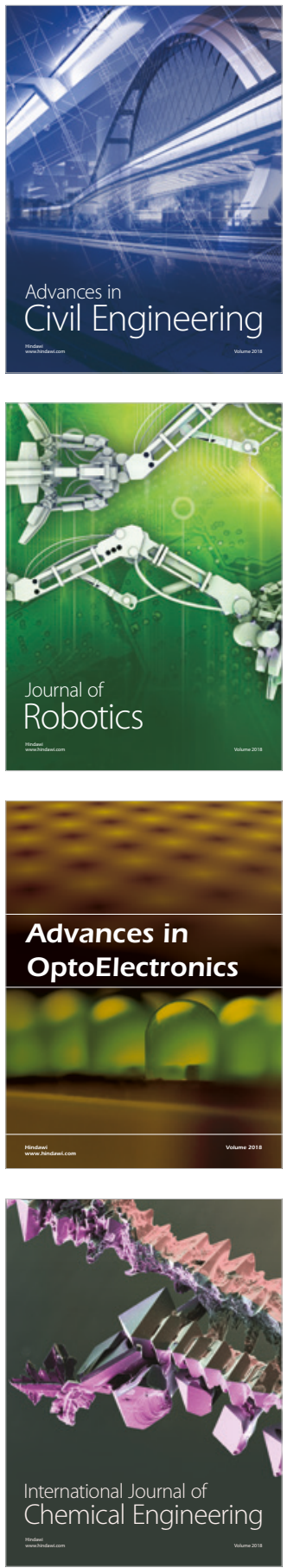

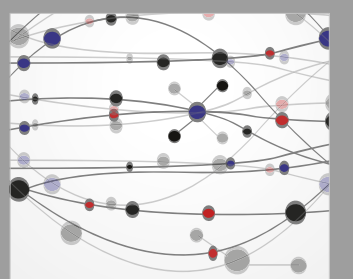

\section{Rotating \\ Machinery}

The Scientific World Journal

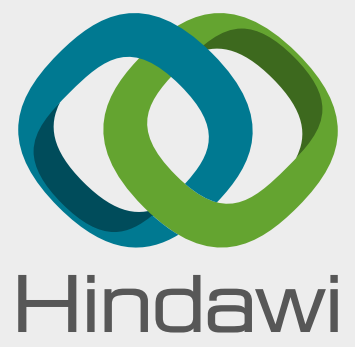

Submit your manuscripts at

www.hindawi.com
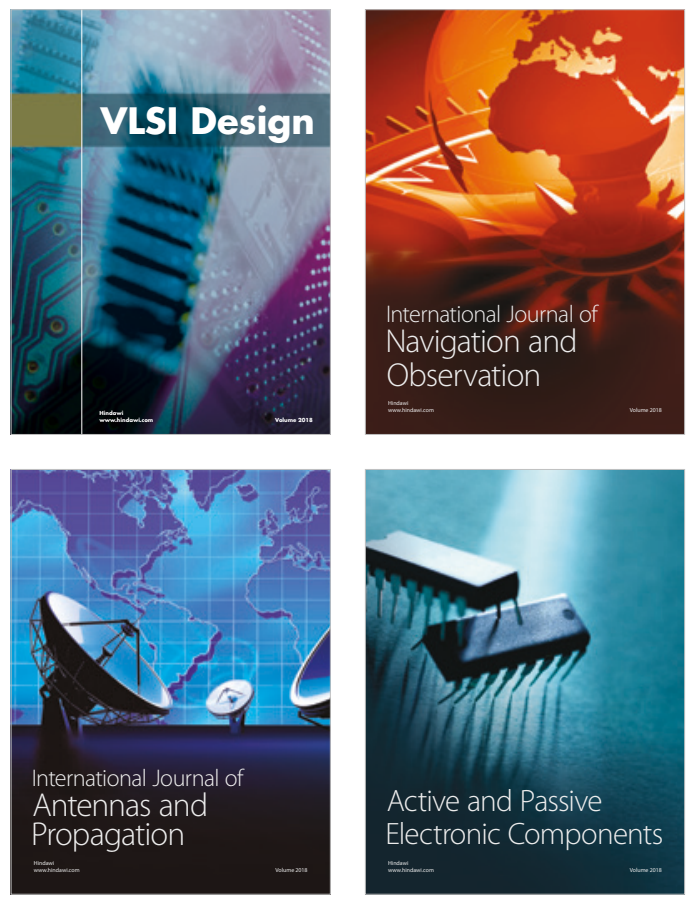
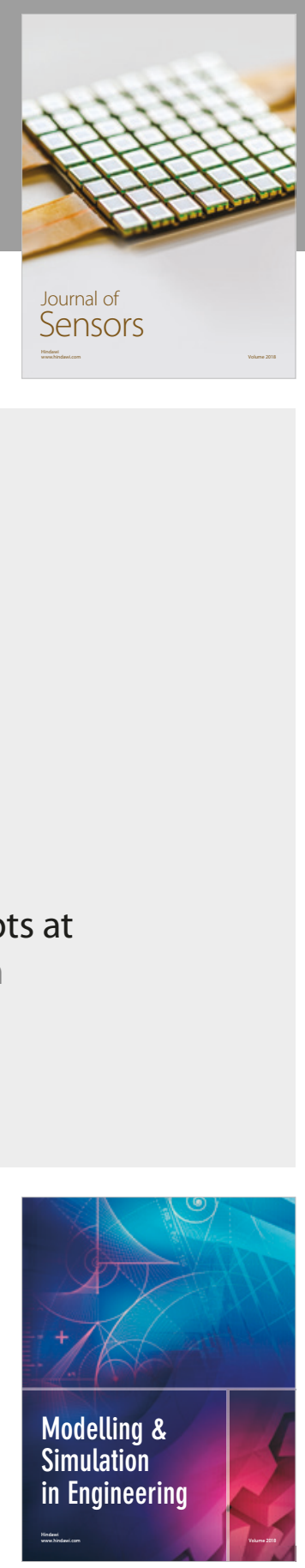

\section{Advances \\ Multimedia}
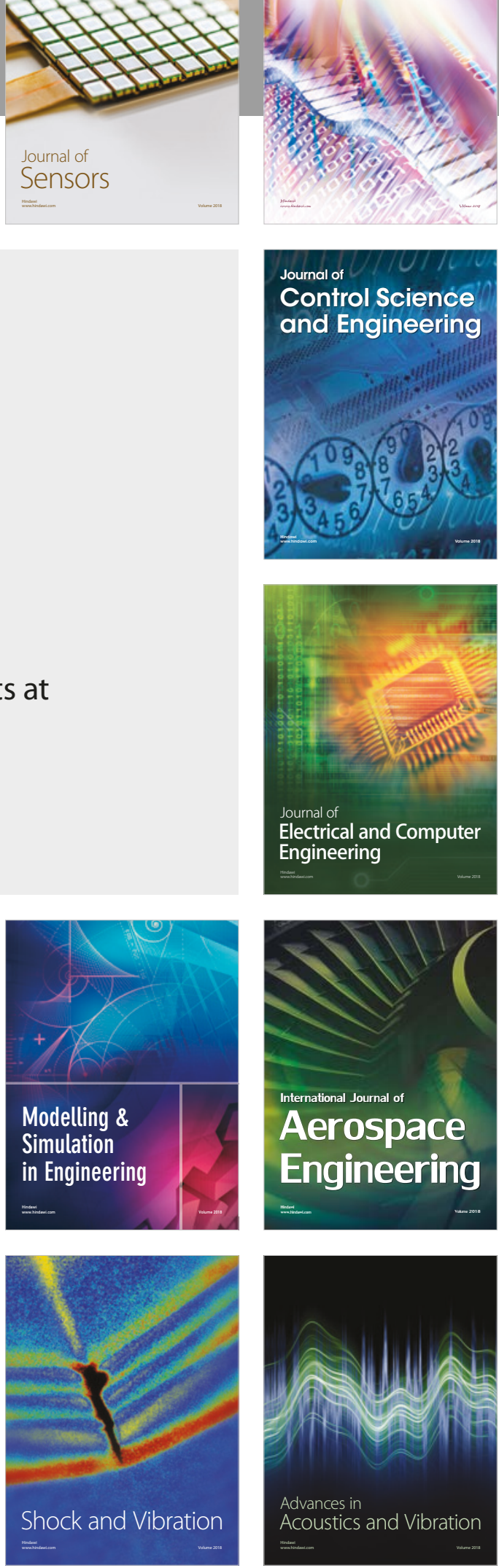